Article

\title{
Two New Alkaloids from Narcissus serotinus L.
}

Natalia B. Pigni ${ }^{1}$, Strahil Berkov ${ }^{1}$, Abdelaziz Elamrani ${ }^{2}$, Mohammed Benaissa ${ }^{2}$, Francesc Viladomat ${ }^{1}$, Carles Codina ${ }^{1}$ and Jaume Bastida ${ }^{1, *}$

1 Department of Natural Products, Plant Biology and Soil Science, Faculty of Pharmacy, University of Barcelona, Barcelona, Spain

2 Department of Chemistry, Faculty of Sciences Ain Chock, University Hassan II, Casablanca, Morocco

* Author to whom correspondence should be addressed; E-Mail: jaumebastida@ub.edu; Tel.: +34 934020268.

Received: 15 September 2010; in revised form: 5 October 2010 / Accepted: 11 October 2010 / Published: 14 October 2010

\begin{abstract}
The Amaryllidaceae family is well known for the presence of an exclusive group of alkaloids with a wide range of biological activities. Narcissus serotinus L. is a plant belonging to this family and its geographical distribution is mainly located along the Mediterranean coast. In the present work, specimens collected near Casablanca (Morocco) were used to study the alkaloid content of this species. Starting with $350 \mathrm{~g}$ of the whole plant we used standard extraction and purification procedures to obtain fractions and compounds for GC-MS and NMR analysis. As well as five known alkaloids, we isolated two new compounds: 1-O-(3'-acetoxybutanoyl)lycorine and narseronine. The latter has been previously published, but with an erroneous structure.
\end{abstract}

Keywords: Narcissus serotinus; Amaryllidaceae; alkaloids; narseronine; 1-O-(3'-acetoxybutanoyl)lycorine

\section{Introduction}

Plants belonging to the Amaryllidaceae family are well known for the presence of an exclusive group of alkaloids with a wide range of biological activities [1]. Within this group, the genus Narcissus has been extensively used in traditional medicine to treat a variety of health problems. 
Antiviral, antifungal and antitumoral activities are just some of the phamacological effects that have been proven for these alkaloids.

Narcissus serotinus L. is an autumn flowering species and the only member of the monotypic section Serotini. It grows mostly in calcareous sandy soil or maquis in dry coastal areas, and its geographical distribution extends over the coastal southern Mediterranean region, including southern Portugal, southern and eastern Spain, western and eastern Italy, Croatia, much of Greece and Israel, almost all the Mediterranean islands, north-west Morocco, Algeria, Tunisia and Libya [2,3].

The aim of this work is to investigate the alkaloid content of this species through the analysis of specimens collected in Morocco. In a previously published article, Vrondeli et al. [4] described the isolation of a new alkaloid from this species, suggesting a 3-epimacronine isomer. Based on the results reported herein, we propose an alternative structure, which also represents a new compound within the Amaryllidaceae alkaloid family.

\section{Results and Discussion}

The $\mathrm{MeOH}$ extract of the fresh aerial parts and bulbs of $N$. serotinus $\mathrm{L}$. was fractioned according to the methodology described in the experimental section. The GC-MS analysis of fraction B revealed the presence of lycorine. The analysis of fraction A showed a more complex mixture: in addition to lycorine [1,5] we determined the presence of galanthine [1,6], 1-O-(3'-hydroxybutanoyl)lycorine [7], assoanine [8] and hippeastrine [9] together with two new alkaloids (Figure 1). Identification of known compounds and structural elucidation of the new ones were achieved through the combined use of GC-MS, HRMS and one and two-dimensional NMR techniques.

The HRMS of 1 suggested a molecular formula $\mathrm{C}_{22} \mathrm{H}_{26} \mathrm{NO}_{7}$ for $[\mathrm{M}+\mathrm{H}]^{+}$with a parent ion at $\mathrm{m} / \mathrm{z}$ 416.1702 (calc. 416.1704). The EIMS showed a molecular ion $[\mathrm{M}]^{+}$at $\mathrm{m} / \mathrm{z} 415$ (18\%) with a base peak at $\mathrm{m} / \mathrm{z}$ 226. It is interesting to note that the isomer 2-O-(3'-acetoxybutanoyl)lycorine, isolated from Galanthus nivalis [10], shows a very similar fragmentation pattern but with a base peak at $\mathrm{m} / \mathrm{z} 250$. However, the pattern observed for 1 shows the base peak at $m / z 226$ [7]. These empirical cases prove that the GC-MS technique is useful for differentiating between isomers with substituents at position 1 or 2. The ${ }^{1} \mathrm{H}-\mathrm{NMR}$ spectral data of compound 1 and the isomer, 2-O-(3'-acetoxybutanoyl)lycorine, are very similar too, showing the major difference in proton shielding at positions 1 and 2: in $\mathbf{1} \mathrm{H}-1$ is more deshielded $(\delta 5.68)$ than the same proton in the isomer $(\delta 4.51)$ and the inverse situation occurs for H-2, which appears at $\delta 4.23$ in the spectrum of 1 and at $\delta 5.31$ for the isomer. Considering its coupling constant values, we assume that the configuration of $\mathbf{1}$ is the same as that proposed for 2-O(3'-acetoxybutanoyl)lycorine and 1-O-(3'-hydroxybutanoyl)lycorine. The high coupling constant (10.4) observed between $\mathrm{H}-4 \mathrm{a}$ and $\mathrm{H}-10 \mathrm{~b}$ suggests a trans-diaxial configuration. Protons $6 \beta$ and $12 \beta$ are more deshielded than $6 \alpha$ and $12 \alpha$, respectively, because of the cis-lone pair of the nitrogen atom. The combined data suggested for compound 1 the structure of 1-O-(3'-acetoxybutanoyl)lycorine. The ${ }^{1} \mathrm{H}-\mathrm{NMR}, \mathrm{COSY}$ and HSQC data are recorded in Table 1. 
Figure 1. New alkaloids isolated from $N$. serotinus L. 1-O-(3'-acetoxybutanoyl)lycorine (1) and narseronine (2).

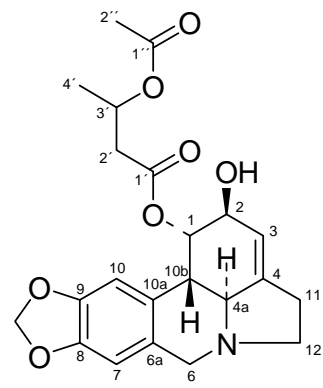

1

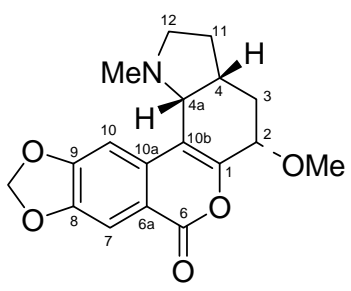

2

Table 1. ${ }^{1} \mathrm{H}-\mathrm{NMR}, \mathrm{COSY}$ and HSQC data of 1-O-(3'-acetoxybutanoyl)lycorine (1).

\begin{tabular}{|c|c|c|c|}
\hline Position & ${ }^{1} \mathrm{H} \delta(\mathrm{J}$ in $\mathrm{Hz})$ & COSY & HSQC \\
\hline 1 & $5.68 s$ & $\mathrm{H}-2, \mathrm{H}-10 \mathrm{~b}$ & $72.5 d$ \\
\hline 2 & $4.23 d t(3.3,1.7)$ & H-1, H-3, H-11 & $69.4 d$ \\
\hline 3 & $5.56 \mathrm{~m}$ & $\mathrm{H}-2, \mathrm{H}-11$ & $116.9 d$ \\
\hline $4 \mathrm{a}$ & $2.76 d(10.4)$ & $\mathrm{H}-10 \mathrm{~b}$ & $61.9 d$ \\
\hline $6 \alpha$ & $3.54 d(14.1)$ & H- $6 \beta$ & $56.6 t$ \\
\hline $6 \beta$ & $4.16 d(14.1)$ & $H-6 \alpha$ & $56.6 t$ \\
\hline 7 & $6.58 \mathrm{~s}$ & & $107.3 d$ \\
\hline 10 & $6.72 \mathrm{~s}$ & & $104.8 d$ \\
\hline $10 \mathrm{~b}$ & $2.91 d(10.4)$ & $\mathrm{H}-1, \mathrm{H}-4 \mathrm{a}$ & $38.8 d$ \\
\hline $11(2 \mathrm{H})$ & $2.65 \mathrm{~m}$ & $\mathrm{H}-2, \mathrm{H}-3, \mathrm{H}-12 \alpha, \mathrm{H}-12 \beta$ & $28.4 t$ \\
\hline $12 \alpha$ & $2.42 d d(9.3,5.0)$ & $\mathrm{H}-11, \mathrm{H}-12 \beta$ & $53.4 t$ \\
\hline $12 \beta$ & $3.38 d t(9.2,4.8)$ & H-11, H-12 $\alpha$ & $53.4 t$ \\
\hline $\mathrm{OCH}_{2} \mathrm{O}$ & $5.92 \mathrm{~s}$ & & $100.8 t$ \\
\hline $2{ }_{\mathrm{A}}^{\prime}$ & $2.43 d d(15.5,5.4)$ & $\mathrm{H}-2^{\prime}{ }_{\mathrm{B}}, \mathrm{H}-3^{\prime}$ & $40.5 t$ \\
\hline $2^{\prime}{ }_{\mathrm{B}}$ & $2.53 d d(15.5,7.8)$ & $\mathrm{H}-2^{\prime}{ }_{\mathrm{A}}, \mathrm{H}-3^{\prime}$ & $40.5 t$ \\
\hline $3^{\prime}$ & $5.10 \mathrm{~m}$ & $\mathrm{H}-{ }^{\prime}{ }_{\mathrm{A}}, \mathrm{H}-2_{\mathrm{B}}{ }_{\mathrm{B}}, \mathrm{H}-4^{\prime}$ & $66.9 d$ \\
\hline $4^{\prime}$ & $1.14 d(6.3)$ & $\mathrm{H}-3^{\prime}$ & $19.3 q$ \\
\hline $\mathrm{AcO}\left(2^{\prime \prime}\right)$ & $1.95 \mathrm{~s}$ & & $20.7 q$ \\
\hline
\end{tabular}

The HRMS analysis of narseronine (2) suggested a molecular formula $\mathrm{C}_{18} \mathrm{H}_{20} \mathrm{NO}_{5}$ for the parent ion $[\mathrm{M}+\mathrm{H}]^{+}$at $\mathrm{m} / \mathrm{z} 330.1340$ (calc. 330.1336). This indicates a molecular formula $\mathrm{C}_{18} \mathrm{H}_{19} \mathrm{NO}_{5}$, in accordance with a molecular weight of 329. The EIMS showed a molecular ion $[\mathrm{M}]^{+}$at $\mathrm{m} / \mathrm{z} 329$ (20\%). The mass spectral fragmentation pattern is not similar to those commonly shown by the homolycorine type compounds, because of the absence of a double bond between C-3 and C-4. The unusual occurence of a double bond at position $\mathrm{C}-1 / \mathrm{C}-10 \mathrm{~b}$ probably drastically changes this pattern. Its ${ }^{1} \mathrm{H}$ NMR spectrum exhibited two singlets at $\delta 7.66$ and 7.29 for the para-oriented aromatic prontons $\mathrm{H}-7$ and $\mathrm{H}-10$, respectively, with $\mathrm{H}-7$ more deshielded due to the peri-carbonyl group [1]. Also, the NOESY experiment showed the spatial proximity between $\mathrm{H}-10$ and the $N$-methyl group. Two doublets appeared at $\delta 6.10$ and $\delta 6.12$ for the protons of the methylendioxy group. A triplet at $\delta 4.22$ was assigned to H-2, coupled to $\mathrm{H}-3$ with a $J=6.1 \mathrm{~Hz}$, suggesting an equatorial orientation with a similar dihedral angle between H-2 and the two H-3 protons; this is consistent with the $\alpha$ position of the methoxy group at C-2 and with the NOESY correlation of this substituent with H-11. A doublet at 
$\delta 3.94$, was undoubtedly assigned to $\mathrm{H}-4 \mathrm{a}$ for a $3 \mathrm{JC}-\mathrm{H} \mathrm{HMBC}$ correlation with the $\mathrm{N}$-methyl group; COSY experiment showed its only correlation with $\mathrm{H}-4$, with a $J=6.4 \mathrm{~Hz}$ suggesting a cis- C/D ring fusion $[11,12]$. The spectrum also showed, between the most significant signals, a singlet integrating for 3 protons at $\delta 3.57$ assigned to the methoxy group at C-2, a doublet of triplets at $\delta 3.05$, assigned to $\mathrm{H}-12 \alpha$, more deshielded than $\mathrm{H}-12 \beta$ because of the cis-lone pair of the nitrogen atom [1], a singlet corresponding to the $N$-methyl group at $\delta 2.41$, also supporting the cis-C/D ring junction if we consider the empirical correlations of $N$-methyl chemical shifts with stereochemical assignments suggested by Jeffs et al. [11]; and a doublet of triplets at $\delta 2.01$ assigned to $\mathrm{H}-3 \alpha$, showing spatial proximity with the $\mathrm{O}-\mathrm{CH}_{3}$ group in the NOESY experiment. The NMR spectral data is shown in Table 2.

Narseronine was previously isolated by Vrondeli et al. [4] but published with an erroneous structure. They suggested a 3-epimacronine isomer, a tazettine type alkaloid but their mass spectral fragmentation proposal does not explain the occurrence of the most abundant peaks of the mass spectrum, such as $\mathrm{m} / \mathrm{z} 240$ or 241 . Also, the ${ }^{1} \mathrm{H}-\mathrm{NMR}$ assignment is not adequate, including, for instance, the protons in an $\alpha$-position to the $N$-methyl group (H-6 in their numbering system) at $\delta$ 2.30-1.80 ppm, a more shielded displacement than can be expected for a proton in such an electronic environment.

Table 2. ${ }^{1} \mathrm{H}-\mathrm{NMR}, \mathrm{COSY}, \mathrm{NOESY},{ }^{13} \mathrm{C}-\mathrm{NMR}$ (HSQC) and HMBC data of narseronine (2).

\begin{tabular}{|c|c|c|c|c|c|}
\hline Position & ${ }^{1} \mathbf{H} \boldsymbol{\delta}(\mathbf{J}$ in $\mathbf{H z})$ & COSY & NOESY & ${ }^{13} \mathrm{C} \delta$ & НМВC \\
\hline 1 & - & - & - & $152.9 \mathrm{~s}$ & - \\
\hline 2 & $4.22 t(6.1)$ & $\mathrm{H}-3 \alpha, \mathrm{H}-3 \beta$ & $\mathrm{H}-3 \alpha, \mathrm{H}-3 \beta, \mathrm{OCH}_{3}$ & $74.9 d$ & $\begin{array}{l}\mathrm{C}-1, \mathrm{C}-3, \mathrm{C}-4 \\
\mathrm{C}-10 \mathrm{~b}, \mathrm{OCH}_{3}\end{array}$ \\
\hline $3 \alpha$ & $\begin{array}{l}2.01 d t \\
(13.5,5.5)\end{array}$ & H-2, H-3 $\beta, H-4$ & $\begin{array}{l}\mathrm{H}-2, \mathrm{H}-3 \beta, \mathrm{H}-4, \\
\mathrm{OCH}_{3}\end{array}$ & $31.4 t$ & $\begin{array}{l}\text { C-1, C-2, C-4, C-4a, } \\
\text { C-11 }\end{array}$ \\
\hline $3 \beta$ & $\begin{array}{l}2.22-2.13 \mathrm{~m} \\
\text { (overlapped) }\end{array}$ & $\mathrm{H}-2, \mathrm{H}-3 \alpha, \mathrm{H}-4$ & $\begin{array}{l}\mathrm{H}-2, \mathrm{H}-3 \alpha, \mathrm{H}-4, \\
\mathrm{OCH}_{3}\end{array}$ & $31.4 t$ & $\begin{array}{l}\text { C-1, C-2, C-4, C-4a, } \\
\text { C-11 }\end{array}$ \\
\hline 4 & $2.64 \mathrm{~m}$ & $\begin{array}{l}H-3 \alpha, H-3 \beta, H-4 a, \\
H-11 \alpha, H-11 \beta\end{array}$ & $\begin{array}{l}H-3 \alpha, H-3 \beta, H-4 a, \\
H-11 \alpha, H-11 \beta\end{array}$ & $35.1 \mathrm{~d}$ & $\mathrm{C}-12$ \\
\hline $4 a$ & $3.94 d(6.4)$ & $\mathrm{H}-4$ & $\mathrm{H}-4, \mathrm{H}-10, \mathrm{NCH}_{3}$ & $61.6 d$ & $\begin{array}{l}\mathrm{C}-1, \mathrm{C}-3, \mathrm{C}-4, \mathrm{C}-10 \mathrm{a}, \mathrm{C}- \\
10 \mathrm{~b}, \mathrm{C}-11, \mathrm{C}-12, \mathrm{NCH}_{3}\end{array}$ \\
\hline 6 & - & - & - & $161.5 \mathrm{~s}$ & - \\
\hline $6 a$ & - & - & - & $116.4 s$ & - \\
\hline 7 & $7.66 \mathrm{~s}$ & - & - & $107.8 d$ & C-6, C-8, C-9, C-10a \\
\hline 8 & - & - & - & $148.4 \mathrm{~s}$ & - \\
\hline 9 & - & - & - & $153.8 \mathrm{~s}$ & - \\
\hline 10 & $7.29 \mathrm{~s}$ & - & $\mathrm{H}-4 \mathrm{a}, \mathrm{NCH}_{3}$ & $103.3 d$ & C-6a, C-8, C-9, C-10b \\
\hline $10 \mathrm{a}$ & - & - & - & $135.1 \mathrm{~s}$ & - \\
\hline $10 \mathrm{~b}$ & - & - & - & $110.8 s$ & - \\
\hline $11 \alpha$ & $\begin{array}{l}2.22-2.13 \mathrm{~m} \\
\text { (overlapped) }\end{array}$ & $\begin{array}{l}\mathrm{H}-4, \mathrm{H}-11 \beta, \\
\mathrm{H}-12 \alpha, \mathrm{H}-12 \beta\end{array}$ & $\begin{array}{l}\mathrm{H}-4, \mathrm{H}-11 \beta, \mathrm{H}-12 \alpha, \\
\mathrm{H}-12 \beta, \mathrm{OCH}_{3}\end{array}$ & $29.6 t$ & $C-3, C-4 a$ \\
\hline $11 \beta$ & $\begin{array}{l}1.90 d d d \\
(12.6,8.3,4.2)\end{array}$ & $\begin{array}{l}\mathrm{H}-4, \mathrm{H}-11 \alpha \\
\mathrm{H}-12 \alpha, \mathrm{H}-12 \beta\end{array}$ & $\begin{array}{l}\mathrm{H}-4, \mathrm{H}-11 \alpha, \mathrm{H}-12 \alpha, \\
\mathrm{H}-12 \beta, \mathrm{OCH}_{3}\end{array}$ & $29.6 t$ & $C-3, C-4 a$ \\
\hline $12 \alpha$ & $\begin{array}{l}3.05 d t \\
(11.0,7.6)\end{array}$ & $\begin{array}{l}\mathrm{H}-11 \alpha, \mathrm{H}-11 \beta, \\
\mathrm{H}-12 \beta\end{array}$ & $\begin{array}{l}\mathrm{H}-11 \alpha, \mathrm{H}-11 \beta \\
\mathrm{H}-12 \beta, \mathrm{NCH}_{3}\end{array}$ & $54.3 t$ & $\mathrm{C}-4, \mathrm{C}-4 \mathrm{a}, \mathrm{C}-11, \mathrm{NCH}_{3}$ \\
\hline $12 \beta$ & $2.81 \mathrm{~m}$ & $\begin{array}{l}\text { H-11 } \alpha, H-11 \beta \\
H-12 \alpha\end{array}$ & $\begin{array}{l}\mathrm{H}-11 \alpha, \mathrm{H}-11 \beta \\
\mathrm{H}-12 \alpha, \mathrm{NCH}_{3}\end{array}$ & $54.3 t$ & $\mathrm{C}-4, \mathrm{C}-4 \mathrm{a}, \mathrm{C}-11, \mathrm{NCH}_{3}$ \\
\hline $\mathrm{OCH}_{2} \mathrm{O}$ & $\begin{array}{l}6.10 d(1.2) \\
6.12 d(1.2)\end{array}$ & - & - & $102.4 t$ & C-8, C-9 \\
\hline $\mathrm{OCH}_{3}$ & $3.57 \mathrm{~s}$ & - & $\begin{array}{l}\text { H-2, H-3 } \alpha, H-3 \beta \\
H-11 \alpha, H-11 \beta\end{array}$ & $58.3 q$ & $\mathrm{C}-2$ \\
\hline $\mathrm{NCH}_{3}$ & $2.41 \mathrm{~s}$ & - & $\begin{array}{l}\text { H-2, H-3 } \alpha, H-3 \beta \\
H-11 \alpha, H-11 \beta\end{array}$ & $41.8 q$ & C-4a, C-12 \\
\hline
\end{tabular}




\section{Experimental}

\subsection{General}

NMR spectra were recorded in a Mercury $400 \mathrm{MHz}$ or a Varian VXR $500 \mathrm{MHz}$, instrument using $\mathrm{CDCl}_{3}$ as the solvent and TMS as the internal standard. Chemical shifts were reported in $\delta$ units (ppm) and coupling constants $(J)$ in Hz. EIMS were obtained on a GC-MS Agilent $6890+$ MSD 5975 operating in EI mode at $70 \mathrm{eV}$. A HP-5 MS column $(30 \mathrm{~m} \times 0.25 \mathrm{~mm} \times 0.25 \mu \mathrm{m})$ was used. The temperature program was: $100-180^{\circ} \mathrm{C}$ at $15{ }^{\circ} \mathrm{C} \mathrm{min}{ }^{-1}, 1 \mathrm{~min}$ hold at $180{ }^{\circ} \mathrm{C}, 180-300{ }^{\circ} \mathrm{C}$ at $5{ }^{\circ} \mathrm{C} \mathrm{min}^{-1}$ and $1 \mathrm{~min}$ hold at $300{ }^{\circ} \mathrm{C}$. Injector temperature was $280^{\circ} \mathrm{C}$. The flow rate of carrier gas (Helium) was $0.8 \mathrm{~mL} \mathrm{~min}^{-1}$. In most cases the split ratio was 1:20, but with more diluted samples a split ratio of 1:5 was applied. UV spectra were obtained on a DINKO UV2310 instrument and IR spectra were recorded on a Nicolet Avatar 320 FT-IR spectrophotometer.

\subsection{Plant material}

Whole plants of Narcissus serotinus L. (Amaryllidaceae) were collected in October 2009 during the flowering period in Ben Slimane, near Casablanca (Morocco), and identified by Professor El Ghazi. A voucher sample (MB-026/2009) was deposited at the Herbarium of the Faculty of Sciences Ain Chock, University Hassan II.

\subsection{Extraction and isolation of alkaloids}

The fresh whole plant $(350 \mathrm{~g})$ was crushed and extracted with methanol $(1 \times 800 \mathrm{~mL}, 24 \mathrm{~h}$; $1 \times 800 \mathrm{~mL}, 72 \mathrm{~h}$; and $2 \times 400 \mathrm{~mL}, 48 \mathrm{~h}$ each). The extract was evaporated under reduced pressure to yield $5.5 \mathrm{~g}$. This crude extract was dissolved in $100 \mathrm{~mL}$ of $\mathrm{H}_{2} \mathrm{SO}_{4} 1 \%(\mathrm{v} / \mathrm{v})$ and neutral material was removed with $\mathrm{Et}_{2} \mathrm{O}(6 \times 100 \mathrm{~mL})$. The acidic soln. was basified with $25 \%$ ammonia up to $\mathrm{pH} 9-10$ and extracted with EtOAc $(3 \times 100 \mathrm{~mL})$ to give extract A $(149.4 \mathrm{mg})$. Another extraction with EtOAc $(2 \times 100 \mathrm{ml})$ gave extract $\mathrm{B}(23 \mathrm{mg})$. Both fractions were dried with anhydrous $\mathrm{Na}_{2} \mathrm{SO}_{4}$, filtered and completely dried under reduced pressure. Referred to the fresh weight, the sum of these two extracts represents approximately $0.05 \%$. After dissolving A and $\mathrm{B}$ in $\mathrm{MeOH}$, lycorine crystallized directly. Extract A was subjected to a vacuum liquid chromatography (VLC) [13] using a silica gel 60 A (6-35 $\mu$ ) column with a diameter of $1 \mathrm{~cm}$ and a height of $4 \mathrm{~cm}$. Alkaloids were eluted using hexane gradually enriched with EtOAc, and then EtOAc gradually enriched with $\mathrm{MeOH}$. Fractions of $10 \mathrm{~mL}$ were collected (105 in total) monitored by TLC (Dragendorff's reagent, UV $254 \mathrm{~nm}$ ) and combined according to their profiles. Five main fractions were obtained and subjected to preparative TLC (20 cm $\times 20 \mathrm{~cm} \times 0.25 \mathrm{~mm}$, silica gel 60F254). Narseronine (2, $4.5 \mathrm{mg})$ and 1-O-(3'-acetoxybutanoyl)lycorine (1, $1.5 \mathrm{mg}$ ) were obtained in major quantities from fractions 32-38 (eluted from VLC with hexaneEtOAc, 30:70 to 20:80) through preparative TLC (EtOAc-hexane 4:1 + 25\% ammonia).

1-O-(3'-Acetoxybutanoyl)lycorine (1). UV (MeOH) $\lambda_{\max } \mathrm{nm}: 368.0,260.0$. IR $\left(\mathrm{CHCl}_{3}\right) v_{\max } \mathrm{cm}^{-1}$ : 2959, 2924, 2853, 1735, 1461, 1371, 1244, 1170, 1038, 776. ${ }^{1} \mathrm{H}-\mathrm{NMR}, \mathrm{COSY}, \mathrm{HSQC}(400 \mathrm{MHz}, 500$ $\mathrm{MHz}, \mathrm{CDCl}_{3}$ ) see Table 1. EIMS 70eV (rel. int.): 416 (4), 415 (18), 354 (1), 269 (12), 268 (37), 250 
(27), 227 (75), 226 (100), 192 (4), 147 (5), 96 (4), 69 (15), 43 (27). HRMS of $[\mathrm{M}+\mathrm{H}]^{+} \mathrm{m} / \mathrm{z} 416.1702$ (Calc. 416.1704 for $\mathrm{C}_{22} \mathrm{H}_{26} \mathrm{NO}_{7}$ ).

Narseronine (2). UV (MeOH) $\lambda_{\max } \mathrm{nm}: 322.5,286.0,241.5$. IR $\left(\mathrm{CHCl}_{3}\right) v_{\max } \mathrm{cm}^{-1}: 2928,1718,1503$, 1482, 1415, 1283, 1256, 1162, 1106, 1035, 935, 754. ${ }^{1} \mathrm{H}-\mathrm{NMR}$, COSY, NOESY, HSQC, HMBC and ${ }^{13} \mathrm{C}-\mathrm{NMR}\left(500 \mathrm{MHz}, \mathrm{CDCl}_{3}\right.$ ) see Table 2. EI-MS 70eV (rel. int.): 329 (20), 328 (21), 314 (2), 299 (28), 272 (38), 271 (18), 256 (46), 255 (16), 254 (30), 242 (34), 241 (98), 240 (100), 228 (13), 213 (18), 212 (13), 59 (42), 57 (60), 44 (37). HRMS of $[\mathrm{M}+\mathrm{H}]^{+} \mathrm{m} / \mathrm{z} 330.1340$ (Calc. 330.1336 for $\mathrm{C}_{18} \mathrm{H}_{20} \mathrm{NO}_{5}$ ).

\section{Conclusions}

These results lead us to conclude that $N$. serotinus L. is an interesting source of alkaloids with potential pharmacological activities. Lycorine type alkaloids have shown notable properties as potent antimalarial and antitrypanosomal agents [7]. Recent investigations, including structure-activity studies, have also demonstrated they are potent inducers of apoptosis with good antitumoral activities $[5,14]$. In this sense, 1-O-(3'-acetoxybutanoyl)lycorine (1) is an attractive candidate for research in these areas. The isolation of narseronine (2) is also promising; this is the first report of a double bond between $\mathrm{C}-1$ and $\mathrm{C}-10 \mathrm{~b}$ in a homolycorine type structure, a feature that confers rigidity to the portion of the molecule formed by A-B rings, and also has a stabilising effect due to the extended conjugated system. This could be an interesting characteristic for potential biological activities related with pharmocophores with such requirements. In other respects, previous reports of antifungal activity of homolycorine-related structures such as hippeastrine [15], suggest narseronine has potential activity as an antifungal agent.

\section{Acknowledgements}

The authors are grateful for the collaboration of SCT-UB technicians. N. Pigni thanks the Spanish Ministerio de Educación for a FPU fellowship. This work was performed within the framework of project AECID A/019023/08. The authors also thank Generalitat de Catalunya (2009-SGR1060) for financial support.

\section{References and Notes}

1. Bastida, J.; Lavilla, R.; Viladomat, F. Chemical and biological aspects of Narcissus alkaloids. In The Alkaloids; Cordell, G.A., Ed.; Elsevier Scientific Publishing: Amsterdam, The Netherlands, 2006; Volume 63, pp. 87-179.

2. Blanchard, J.W. Narcissus. A Guide to Wild Daffodils; Alpine Garden Society: Surrey, UK, 1990; pp. 40-42.

3. Díaz Lifante, Z.; Andrés Camacho, C. Morphological variation of Narcissus serotinus L. s.l. (Amaryllidaceae) in the Iberian Peninsula. Bot. J. Linn. Soc. 2007, 154, 237-257.

4. Vrondeli, A.; Kefalas, P.; Kokkalou, E. A new alkaloid from Narcissus serotinus L. Pharmazie 2005, 60, 559-560. 
5. Lamoral-Theys, D.; Andolfi, A.; Van Goietsenoven, G.; Cimmino, A.; Le Calvé, B.; Wauthoz, N.; Mégalizzi, V.; Gras, T.; Bruyère, C.; Dubois, J.; Mathieu, V.; Kornienko, A.; Kiss, R.; Evidente, A. Lycorine, the main phenanthridine Amaryllidaceae alkaloid, exhibits significant antitumor activity in cancer cells that display resistance to proapoptotic stimuli: an investigation of structure-activity relationship and mechanistic insight. J. Med. Chem. 2009, 52, 6244-6256.

6. Berkov, S.; Bastida, J.; Sidjimova, B.; Viladomat, F.; Codina, C. Phytochemical differentiation of Galanthus nivalis and Galanthus elwesii (Amaryllidaceae): A case study. Biochem. Syst. Ecol. 2008, 36, 638-645.

7. Toriizuka, Y.; Kinoshita, E.; Kogure, N.; Kitajima, M.; Ishiyama, A.; Otoguro, K.; Yamada, H.; Omura, S.; Takayama, H. New lycorine-type alkaloid from Lycoris traubii and evaluation of antitrypanosomal and antimalarial activities of lycorine derivatives. Bioorg. Med. Chem. 2008, 16, 10182-10189.

8. Llabrés, J.M.; Viladomat, F.; Bastida, J.; Codina, C.; Rubiralta, M. Phenantridine alkaloids from Narcissus assoanus. Phytochemistry 1986, 25, 2637-2638.

9. Almanza, G.R.; Fernández, J.M.; Wakori, E.W.T.; Viladomat, F.; Codina, C.; Bastida, J. Alkaloids from Narcissus cv. Salome. Phytochemistry 1996, 43, 1375-1378.

10. Berkov, S.; Codina, C.; Viladomat, F.; Bastida, J. Alkaloids from Galanthus nivalis. Phytochemistry 2007, 68, 1791-1798.

11. Jeffs, P.W.; Mueller, L.; Abou-Donia, A.H.; Seif El-Din, A.A.; Campau, D. Nobilisine, a new alkaloid from Clivia nobilis. J. Nat. Prod. 1988, 51, 549-554.

12. Evidente, A.; Abou-Donia, A.H.; Darwish, F.A.; Amer, M.E.; Kassem, F.F.; Hammoda, H.A.M.; Motta, A. Nobilisitine A and B, two masanane-type alkaloids from Clivia nobilis. Phytochemistry 1999, 51, 1151-1155.

13. Coll, J.C.; Bowden, B.F. The application of vacuum liquid chromatography to the separation of terpene mixtures. J. Nat. Prod. 1986, 49, 934-936.

14. McNulty, J.; Nair, J.J.; Bastida, J.; Pandey, S.; Griffin, C. Structure-activity studies on the lycorine pharmacophore: A potent inducer of apoptosis in human leukemia cells. Phytochemistry 2009, 70, 913-919.

15. Evidente, A.; Andolfi, A.; Abou-Donia, A.H.; Touema, S.M.; Hammoda, H.M.; Shawky, E.; Motta, A. (-)-Amarbellisine, a lycorine-type alkaloid from Amaryllis belladonna L. growing in Egypt. Phytochemistry 2004, 65, 2113-2118.

Sample Availability: Not available.

(C) 2010 by the authors; licensee MDPI, Basel, Switzerland. This article is an open access article distributed under the terms and conditions of the Creative Commons Attribution license (http://creativecommons.org/licenses/by/3.0/). 